\title{
Effects of Fluorine and Silicon Incorporation on Tribological Performance of Diamond-Like Carbon Films
}

\author{
Chavin Jongwannasiri1 ${ }^{*}$, Satoshi Yoshida ${ }^{2}$, Shuichi Watanabe ${ }^{3}$ \\ ${ }^{1}$ King Mongkut's University of Technology Thonburi (Ratchaburi Learning Park), Ratchaburi, Thailand \\ ${ }^{2}$ Mechanical Systems Engineering Major, Graduate School, Nippon Institute of Technology, Saitama, Japan \\ ${ }^{3}$ Department of Applied Chemistry, Nippon Institute of Technology, Saitama, Japan \\ Email: *chavin.jon@kmutt.ac.th
}

How to cite this paper: Jongwannasiri, C. Yoshida, S. and Watanabe, S. (2019) Effects of Fluorine and Silicon Incorporation on Tribological Performance of Diamond-Like Carbon Films. Materials Sciences and Applications, 10, 170-185.

https://doi.org/10.4236/msa.2019.103014

Received: February 7, 2019

Accepted: March 8, 2019

Published: March 11, 2019

Copyright $\odot 2019$ by author(s) and Scientific Research Publishing Inc. This work is licensed under the Creative Commons Attribution International License (CC BY 4.0).

http://creativecommons.org/licenses/by/4.0/

\begin{abstract}
Diamond-like carbon (DLC) is a metastable amorphous film that exhibits unique properties. However, a number of limitations exist regarding the use of DLC, for instance, its tribological characteristics. In this article, the fluorine and silicon incorporated diamond-like carbon (F-DLC and Si-DLC) films are studied, taking into account the tribological properties of these films compared with pure DLC. The structures of the films were characterized using Auger electron spectroscopy and Raman spectroscopy. The hardness and elastic modulus were evaluated by nanoindentation hardness testing. The friction behavior was assessed using ball-on-disk friction testing and optical microscopy. The results indicated that the deposited DLC films contained 0.6 2.1 at.\% F and 26.7 - 38.4 at.\% Si. A decrease in the hardness and elastic modulus was obtained as $\mathrm{F}$ increased in content, which was the opposite of the behavior observed in the Si-DLC films. This was due to the shifting in the G-peak position, which is related to the $\mathrm{sp}^{3}$ bonding fraction in the film. When measured in ambient air, the addition of Si into the DLC film strongly influenced the friction coefficient, whereas doping with F only slightly influenced the films, as evidenced by their wear scars. In addition, only a 26.7 at.\% Si-DLC film showed a very low friction coefficient when measured in dry air. This was attributed to the formation of silicon-rich transfer layer on the ball surfaces. Therefore, the addition of Si with 26.7 at.\% content to a DLC film can be considered beneficial for improving tribological performance.
\end{abstract}

\section{Keywords}

Fluorine Incorporation, Plasma-Based Ion Implantation, Silicon Incorporation, Tribological Performance 


\section{Introduction}

Diamond-like carbon (DLC) films have been extensively studied as potential materials for many tribological applications due to their excellent properties, including high hardness values, low friction coefficients and high wear resistance [1] [2] [3]. Due to their high intrinsic compressive stress, however, DLC films are easily fractured or even peeled off from the substrate, which limits their widespread application. To overcome these limitations, additional elements such as F, N, O, Si and various metals have been introduced into DLC films [1] [4]. In particular, fluorine-doped DLC and silicon-doped DLC films are of significant interest because of their tribological properties, exhibiting a very low friction coefficient and the potential to improve wear performance in a humid atmosphere [5] [6]. Many researchers have extensively studied the friction behavior of DLC films doped with higher F contents. Hakovirta et al. reported that a 19.7 at.\% F-DLC film tested against ruby $\left(\mathrm{Al}_{2} \mathrm{O}_{3}: \mathrm{Cr}\right)$ exhibited a friction coefficient of 0.10 [7], and Prioli et al. reported that a 35 at.\% F-DLC film tested against $\mathrm{Si}_{3} \mathrm{~N}_{4}$ exhibited a friction coefficient of 0.15 [8]. Additionally, there are many reports in the literature addressing the effect of low Si content on the mechanical properties of DLC films. For instance, Papakonstantinou et al. reported that hardness decreased until the Si content was 20 at.\% [9]. Lee et al. showed that hardness significantly increased as the $\mathrm{Si}$ contents were increased but remained less than 5 at.\%. When the Si content was larger than 5 at.\%, the hardness exhibited a saturated behavior and slightly decreased at 17 at.\% Si [10]. However, existing studies have rarely dealt with the mechanical and tribological properties of DLC films with low $\mathrm{F}$ and high Si contents.

In the present paper, plasma-based ion implantation (PBII) technique was utilized to prepare DLC films incorporated with two different elements, namely, fluorine and silicon (henceforth denoted F-DLC and Si-DLC, respectively). The aim of this study was to investigate the influence of low $\mathrm{F}$ and high Si contents on the tribological properties of DLC films.

\section{Experimental Details}

\subsection{Samples Preparation}

A schematic of the PBII system used for the deposition of the DLC, F-DLC and Si-DLC films on a silicon wafer was previously described in the literature [11]. The samples preparation before deposition process was also explained in details. The DLC, F-DLC and Si-DLC films were deposited by introducing a mixture of gases containing $\mathrm{C}_{2} \mathrm{H}_{2}, \mathrm{CF}_{4}$ and $\mathrm{Si}\left(\mathrm{CH}_{3}\right)_{4}$ or tetramethylsilane (TMS) in a vacuum chamber using the parameters listed in Table 1. A negative-pulsed bias voltage of $5 \mathrm{kV}$ was used for the deposition, and the total thickness of the films was approximately $500 \mathrm{~nm}$. The deposition pressure was also set to $2 \mathrm{~Pa}$.

\subsection{Characterization of the Films}

The structure, mechanical and tribological properties of the films were studied 
Table 1. Relative atomic content of carbon, fluorine, silicon and oxygen in the films.

\begin{tabular}{ccccccc}
\hline Film & Mix gas & Gas ratio & $\mathrm{C}($ at.\%) & $\mathrm{F}($ at.\%) & Si (at.\%) & O (at.\%) \\
\hline DLC & $\mathrm{C}_{2} \mathrm{H}_{2}$ & - & 100.0 & - & - & - \\
F-DLC & $\mathrm{C}_{2} \mathrm{H}_{2}: \mathrm{CF}_{4}$ & $2: 1$ & 97.0 & 0.6 & - & 2.4 \\
& & $1: 1$ & 97.1 & 1.2 & - & 1.7 \\
& & $1: 2$ & 96.6 & 2.1 & - & 1.2 \\
Si-DLC & $\mathrm{C}_{2} \mathrm{H}_{2}$ :TMS & $2: 1$ & 65.8 & - & 26.7 & 7.5 \\
& & $1: 1$ & 60.4 & - & 32.2 & 7.3 \\
& & $1: 2$ & 54.0 & - & 38.4 & 7.6 \\
\hline
\end{tabular}

using several characterization techniques. The relative atomic content was evaluated by Auger electron spectroscopy (JAMP-7800F). The structure of the films was analyzed using Raman spectroscopy (JASCO NRS-1000 DT) at an excitation wavelength of $532 \mathrm{~nm}$ and a spot size of $4 \mu \mathrm{m}$. The Raman spectra in the wavenumber region from $1000-1800 \mathrm{~cm}^{-1}$ were deconvoluted into the Gaussian D and $G$ peaks. The integrated area under the $D$ and $G$ peaks $\left(I_{D}\right.$ and $I_{G}$, respectively) was determined by curve fitting. The hardness and elastic modulus values were measured using a nanoindentation hardness tester (Hysitron, Inc.). A diamond indenter (Berkovich-type) with an indentation load of $1000 \mu \mathrm{N}$ was used in this study. The friction behavior was assessed using ball-on-disk friction testing (RHESCA FPR-2100; Tribotester). The tribological tests were performed under dry air $(0 \% \mathrm{RH})$ and ambient air $(40 \% \mathrm{RH})$ at room temperature $\left(20^{\circ} \mathrm{C}\right)$. A $6 \mathrm{~mm}$ diameter Ti-6Al-4V ball slid over the surface of the films under an applied normal load of $1 \mathrm{~N}$, a rotation radius of $3 \mathrm{~mm}$, a linear speed of $31.4 \mathrm{~mm} / \mathrm{s}$, and 6000 frictional rotations. The morphology of the scar was characterized by optical microscope.

\section{Results and Discussion}

\subsection{Film Composition by Auger Electron Spectroscopy (AES)}

The relative atomic contents of $\mathrm{F}$ and $\mathrm{Si}$ were measured using AES, and they were normalized to a total of 100 at.\% neglecting the hydrogen contribution, which could not be measured. Table 1 gives the relative atomic contents of $\mathrm{C}, \mathrm{F}$, $\mathrm{Si}$ and $\mathrm{O}$ in the films in at.\%. To determine the origin of the oxygen, the surface was sputter-etched with argon ions for $60 \mathrm{sec}$. Oxygen was still found to be present in both the F-DLC and Si-DLC films and is likely to have originated from the gas precursors rather than from exposure of the surface to air [9]. The observed $\mathrm{O}$ may also be attributable to the destruction of the oxide layer on the substrate surface during ion implantation [12]. Since the Si-DLC had more oxygen content in the films, there is a possibility that the Si content in the film was easily oxidized.

\subsection{Film Structure by Raman Spectroscopy}

Raman spectroscopy is one of the most common techniques used to study the 
structural properties of DLC films. The position of the G-peak changing to a lower wavenumber is related to increasing bond-angle disorder or increasing $\mathrm{sp}^{3}$ content, while the $I_{D} / I_{G}$ ratio is proportional to the $\mathrm{sp}^{2} / \mathrm{sp}^{3}$ ratio [13]. These two factors play a major role in assessing the Raman spectra. Figure 1 shows the G-peak position and $\mathrm{I}_{\mathrm{D}} / \mathrm{I}_{\mathrm{G}}$ ratio as a function of the relative atomic contents of $\mathrm{F}$ and $\mathrm{Si}$. The presence of $\mathrm{F}$ in the DLC films resulted in a shifting of the G-peak positions to higher frequencies (from $1536 \mathrm{~cm}^{-1}$ without $\mathrm{F}$ to $1547 \mathrm{~cm}^{-1}$ with 2.1 at.\% $\mathrm{F}$ ) and an increase in the $\mathrm{I}_{\mathrm{D}} / \mathrm{I}_{\mathrm{G}}$ ratio (from 0.55 without $\mathrm{F}$ to 0.63 with 2.1 at.\% F). This was consistent with the results obtained by other authors [14] [15] [16]. The shift in the G-peak position to a higher frequency can be attributed to the increased number of $\mathrm{sp}^{2}$ bonds and the formation of $\mathrm{sp}^{2}$-hybridized carbon domains [17]. Yao et al. suggested that an introduction of $\mathrm{F}$ into DLC films breaks the cross-linked $\mathrm{C}-\mathrm{C}$ bonds; i.e., the $\mathrm{sp}^{3}$ diamond-like matrix collapses, and the $\mathrm{sp}^{2}$-hybridized carbon domains increase in the F-DLC films [18]. Goyenola et al. reported that $\mathrm{C}$ and $\mathrm{F}$ could only form a single bond. The formed $\mathrm{C}-\mathrm{F}$ bond sticks out of the C-C network and disrupts the local carbon microstructure by reducing the formation of large rings and chains [19]. Consequently, the $\mathrm{sp}^{3}$ carbon transforms to $\mathrm{sp}^{2}$ carbon. With increasing $\mathrm{F}$ contents, the large rings continue to grow and accelerate ring interlocking at the edge of the C-C network, leading to the formation of polymer-like structures [20]. Therefore, it can be concluded that incorporation of F into DLC films decreased the $\mathrm{sp}^{3} / \mathrm{sp}^{2}$ ratio and created a more polymer-like structural arrangement in the DLC film.

On the contrary, the presence of $\mathrm{Si}$ in the DLC films exhibited an opposite trend, causing a shift in the G-peak positions toward lower frequencies (from $1536 \mathrm{~cm}^{-1}$ without $\mathrm{Si}$ to $1468 \mathrm{~cm}^{-1}$ with 38.4 at. $\% \mathrm{Si}$ ) and decreasing the $\mathrm{I}_{\mathrm{D}} / \mathrm{I}_{\mathrm{G}}$ ratio (from 0.55 without $\mathrm{Si}$ to 0.21 with 38.4 at.\% Si). This was consistent with the

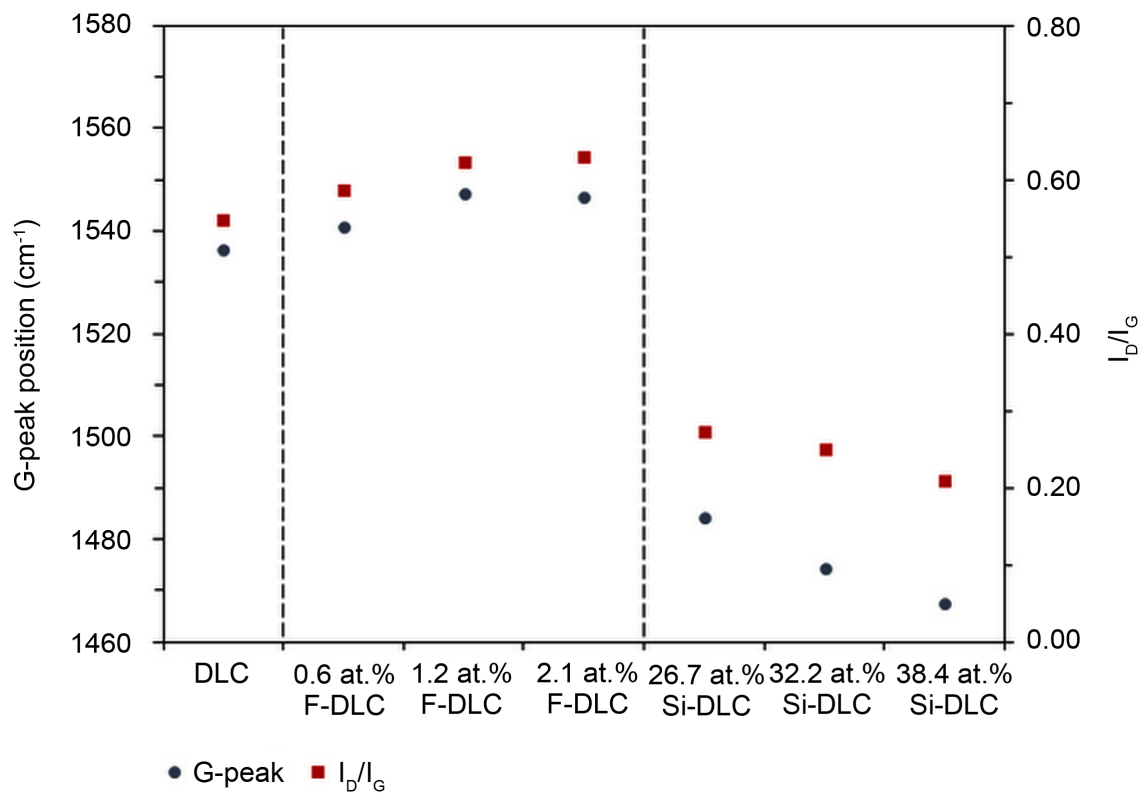

Figure 1. G-peak and $\mathrm{I}_{\mathrm{D}} / \mathrm{I}_{\mathrm{G}}$ of the films as a function of $\mathrm{F}$ and $\mathrm{Si}$ contents. 
results obtained from other authors [21] [22], who indicated that the bonding environment of the DLC is modified after doping the films with silicon. The shift in the G-peak position to a lower frequency can be attributed to the presence of $\mathrm{Si}$ - $\mathrm{C}$ bridging bonds, which can also weaken the adjacent $\mathrm{C}-\mathrm{C}$ bonds, resulting in a frequency shift toward the D-peak, and in longer, de-strained bonds, which vibrated at lower frequencies [9] [23]. These results suggested that the incorporation of $\mathrm{Si}$ into DLC films reduced the average size of the $\mathrm{sp}^{2}$-bonded clusters, acting as an inhibitor to cluster formation, because the addition of $\mathrm{Si}$ is well known to form only four-fold coordinated networks (Si-C).

\subsection{Hardness and Elastic Modulus Values}

The hardness and elastic modulus values of the films as a function of the relative atomic contents of $\mathrm{F}$ and $\mathrm{Si}$ are shown in Figure 2. Each value is the average of six measurements. The nanoindentation tests were performed to a depth less than $10 \%$ of the film thickness to avoid the effect of the substrate. The results indicated that both the hardness and elastic modulus values slightly decreased as the $\mathrm{F}$ content increased, varying from $18.9 \mathrm{GPa}$ and $158 \mathrm{GPa}$ without $\mathrm{F}$ to 17.8 $\mathrm{GPa}$ and $148 \mathrm{GPa}$ at 2.1 at.\% F. In DLC films, the decrease in hardness and elastic modulus is usually associated with a decrease in the $\mathrm{sp}^{3}$ bonding fraction [24]. Yao et al. attributed the decrease in the hardness and elastic modulus to changes in the microstructure since more $\mathrm{sp}^{2}$ bonds were formed in the films due to the increase in the $\mathrm{F}$ content [18]. The substitution of strong $\mathrm{C}=\mathrm{C}$ bonds by weaker $\mathrm{C}-\mathrm{F}$ bonds induced the decrease in hardness and elastic modulus [25]. Jacobsohn et al. suggested that the hardness of the DLC films was caused by the C-C network, which is locally interrupted by $\mathrm{F}$ [26]. The introduction of $\mathrm{F}$ decreased the cross-linking and created a new and more open structural arrangement, leading to decreases in the hardness and elastic modulus.

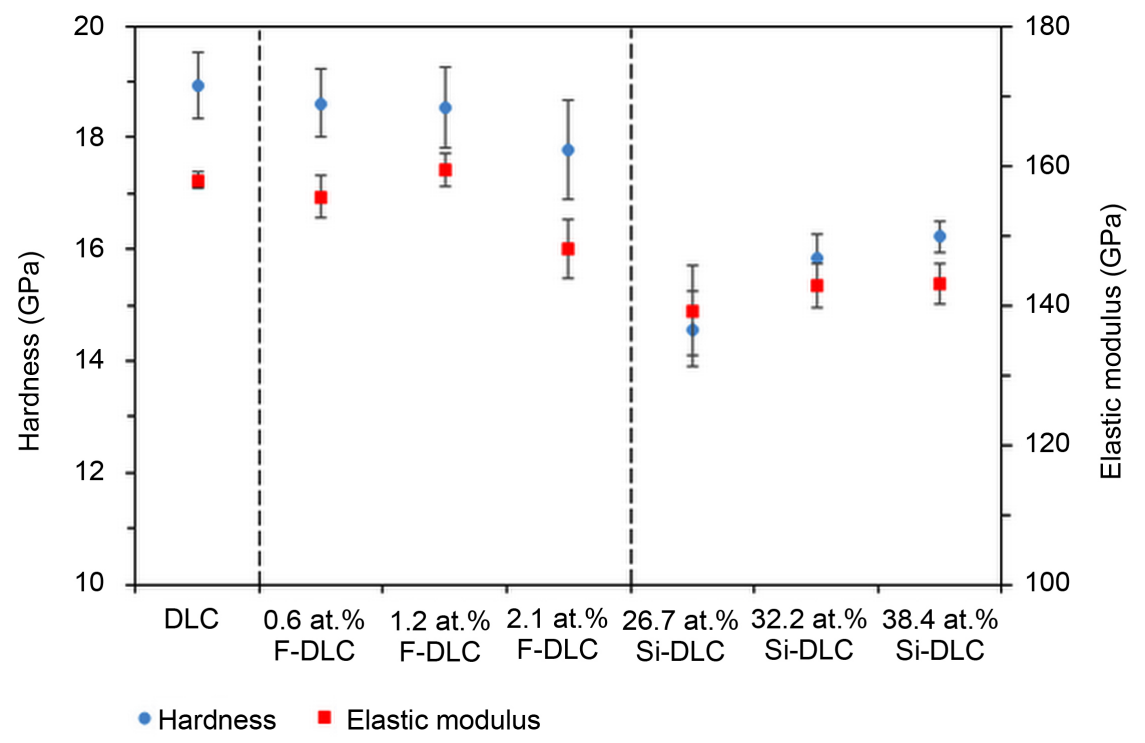

Figure 2. Hardness and elastic modulus of the films as a function of F and Si contents. 
For the Si-DLC films, both the hardness and elastic modulus values first decreased (from $18.9 \mathrm{GPa}$ and $158 \mathrm{GPa}$ without $\mathrm{Si}$ to $14.6 \mathrm{GPa}$ and $139 \mathrm{GPa}$ at 26.7 at.\% Si) and then gradually increased (to $16.2 \mathrm{GPa}$ and $143 \mathrm{GPa}$ at 38.4 at.\% Si). Initially, these results were surprising and contradict those from other authors [24] [27]. That is, an increase in the TMS flow ratio leads to an increase in the hydrogen content in the films. The high hydrogen content in the films enhanced the formation of polymeric $\mathrm{sp}^{3} \mathrm{C}-\mathrm{H}$ bonds, resulting in softer films. However, these contradicting results can be explained if we consider that the films fabricated by our technique were affected by the energy of the colliding particle. Comparing the particle energy between the low and high Si content DLC films, the particles used during film growth with low Si contents may have more energy than those with high Si contents [28]. Highly energetic ion bombardment can destroy the microstructure of the DLC films and generate numerous defects, reducing the hardness and elastic modulus of the films. The effects of the ion bombardment decreased when the Si content increased, and more $\mathrm{sp}^{3}-\mathrm{C}$ and $\mathrm{Si}-\mathrm{C}$ bonds led to a significant increase in the hardness and elastic modulus values. Thus, the change in the colliding particles' energy sufficiently explains the changes in the hardness and elastic modulus of the films. Furthermore, the major contribution to hardness comes from $\mathrm{C}-\mathrm{C}\left(\mathrm{sp}^{3}\right), \mathrm{C}=\mathrm{C}\left(\mathrm{sp}^{2}\right)$ and $\mathrm{Si}-\mathrm{C}\left(\mathrm{sp}^{3}\right)$ bondings. The weakest bond is the $\mathrm{C}=\mathrm{C}\left(\mathrm{sp}^{2}\right)$ bonding [29]. Due to the incorporation of Si into DLC films, some of these $\mathrm{sp}^{2}$-bonded cluster formations will be inhibited (as discussed earlier in Raman results) and replaced by stronger Si-C bonds. Therefore, when more Si content was incorporated into DLC film, it preferentially substituted these $\mathrm{sp}^{2}$-hybridized carbon bonds, removing more of these weak $\mathrm{C}=\mathrm{C}$ bonds as $\mathrm{Si}$ content increased. This leads to an increase in the hardness and elastic modulus of the Si-DLC films with increasing Si content.

\subsection{Friction Tests Measured in Ambient Air}

The friction coefficients of the films with different $\mathrm{F}$ and Si contents measured in ambient air are shown in Figure 3. For comparison, examinations were performed on a pure DLC film under the same conditions. The friction coefficients of the films were calculated from the average steady-state region. As shown in Figure 3(a), the results indicated that the pure DLC film showed a high friction coefficient of approximately 0.18 . As the amount of $F$ slowly increased, the friction coefficients slightly decreased to 0.14 at 2.1 at.\% F. Because the pure DLC film was deposited by hydrogenated plasma, it contained hydrogen. Hydrogenated DLC (a-C:H) films are known to exhibit low friction coefficients in an inert atmosphere or under vacuum [30]. Hydrogen termination of the dangling bonds of surface carbon atoms has been shown to be responsible for the low friction coefficient [30] [31]. When tested in an atmosphere with a high relative humidity, the friction coefficients of a-C:H coatings increased [32]. This can be ascribed to the fact that the polarized $\mathrm{C}-\mathrm{H}$ bonds in a-C:H films absorb water molecules, which have great polarity, onto the film surface through intermolecular 

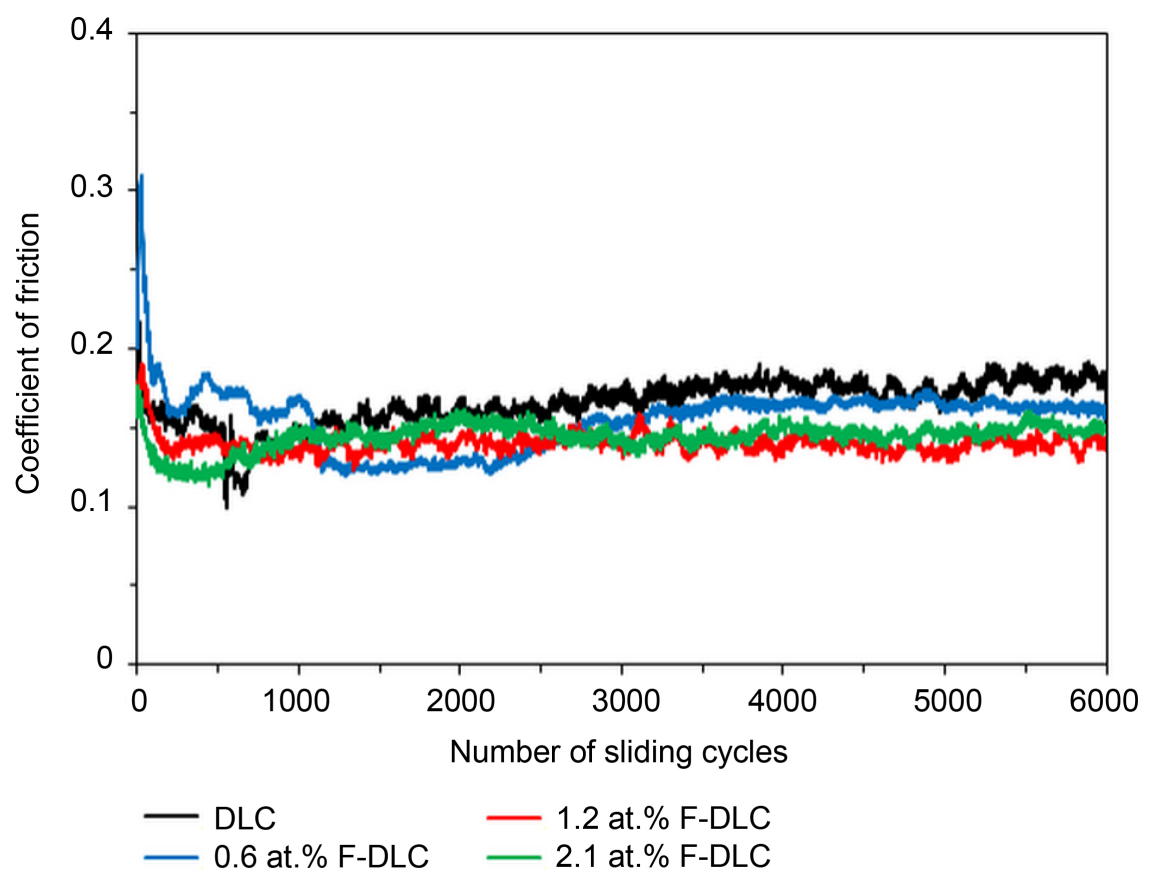

(a)

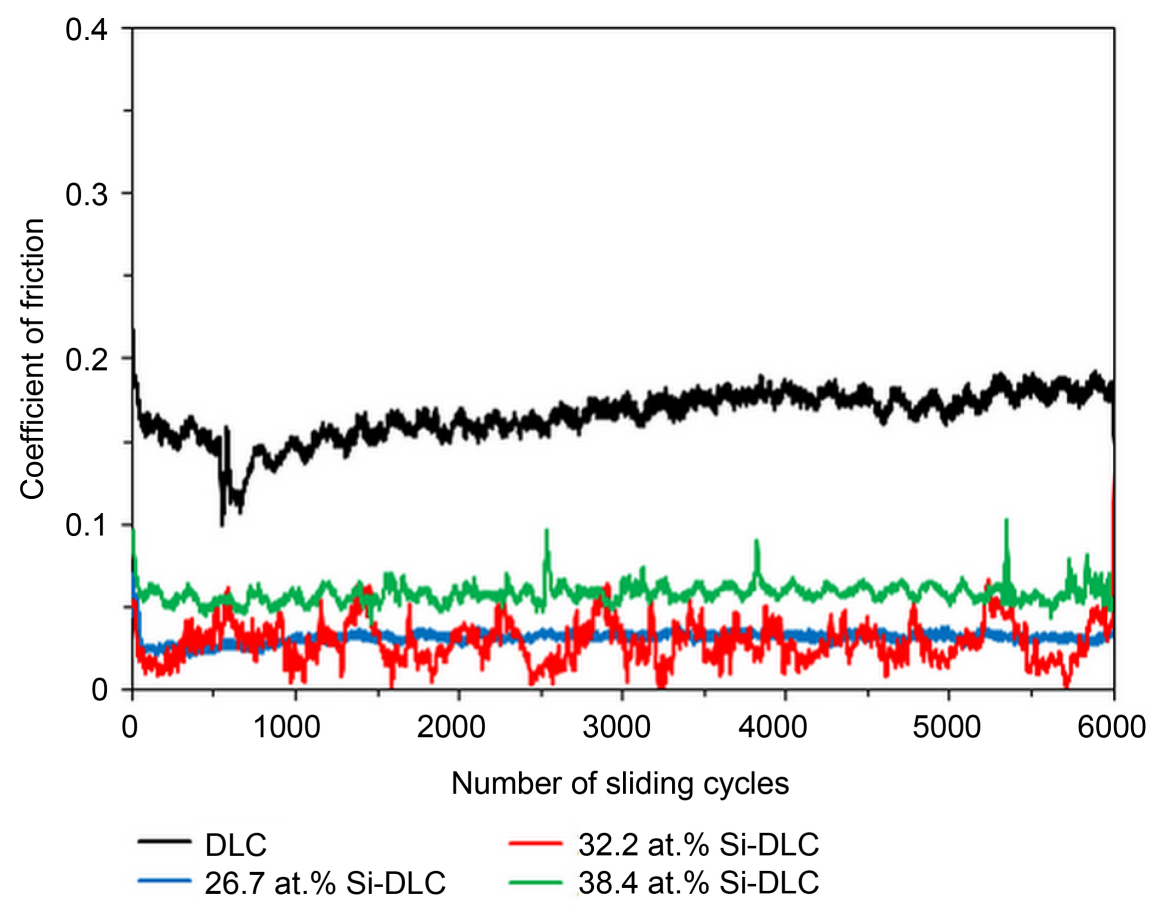

(b)

Figure 3. Friction coefficients of the films with different $\mathrm{F}$ and Si contents compared to that of a pure DLC film measured in ambient air. (a) F-DLC films; (b) Si-DLC films.

forces. The resulting water adsorbed layer leads to a viscous drag and even capillary forces, thus increasing the adhesion and friction of the pure DLC film surface. Similar to the hydrogen atoms discussed above, the passivation of sur- 
face dangling bonds by fluorine atoms can be ascribed to the formation of fluorocarbon groups, which terminate the surface active carbon [33]. Due to the most electronegative element of fluorine [34], the formation of repulsive forces between the film and ball surfaces with fluorine atoms during sliding can occur. Repulsive forces reduce the shear strength of the contact, leading to a weaker lateral friction force, thus lowering the friction coefficient [33]. This may be attributable to the reduction in the friction coefficients for the F-DLC films.

For the Si-DLC films, as shown in Figure 3(b), the friction coefficient values were in the range from 0.01 to 0.06 , which were lower than that of the DLC and F-DLC films. The most stable and lowest friction coefficient of the DLC film surface, approximately 0.03 , was produced by the 26.7 at.\% Si-DLC film. The friction coefficient of the 32.2 at.\% Si-DLC film fluctuated from 0.01 to 0.05 and was lower than that of the 38.4 at.\% Si-DLC film. These results indicated that the DLC film with $\mathrm{Si}$ added had significantly decreased friction coefficients compared to the pure DLC film. This was consistent with the results obtained from other authors [35] [36], who suggested that the decreasing friction coefficient of Si-DLC films was attributable to silica-gel-like sacrificial layers formed during friction tests. Furthermore, debris covering on the ball scar was not ferrous oxide but silicon-rich oxide [37]. Consequently, the formation of an oxide layer is probably the reason for the low friction coefficient.

The tribological behavior of the DLC films under dry sliding contact is normally controlled by a carbon-rich transfer layer formed on the counterpart surfaces, which prevents direct contact between the mating materials and the DLC films and establishes a new sliding interface [38] [39] [40]. To understand the friction behavior of the films, optical micrographs of the ball surfaces from the friction testing of the DLC, F-DLC and Si-DLC films are shown in Figure 4. Considerable differences on the transfer layer and wear scars were observed. A small transfer layer and wear scar area formed on the Ti-6Al-4V ball surfaces when they slid against a pure DLC film (Figure 4(a)). A similar surface morphology was also observed on the DLC film with 0.6 at.\% F (Figure 4(b)). Due to a small amount of F in the DLC film, the friction coefficient was not different compared to that of the pure DLC film. Furthermore, a uniform wearing with small scar and transfer layer formed near the wear scar after adding 1.2 and 2.1 at.\% F to the DLC films, as shown in Figure 4(c) and Figure 4(d). This was consistent with the results obtained by Sen et al., who showed that a transfer layer from an amorphous carbon coating incorporating $\mathrm{F}$ was established on the counterpart material [41]. The easy shear and chemical reactions of the transfer layer were essential to achieve low friction coefficient of the films.

In addition, when adding Si to a DLC film, the wear scar was largely covered by the transfer layer that was formed by agglomerated debris (Figures $4(\mathrm{e})$-(g)). The formation of the transfer layer could dominate the friction behavior. Kim et al. suggested that Si-incorporated DLC enhanced the formation of silicon-rich oxide layer, which acted as a protective coating [42]. Therefore, the oxide layer 


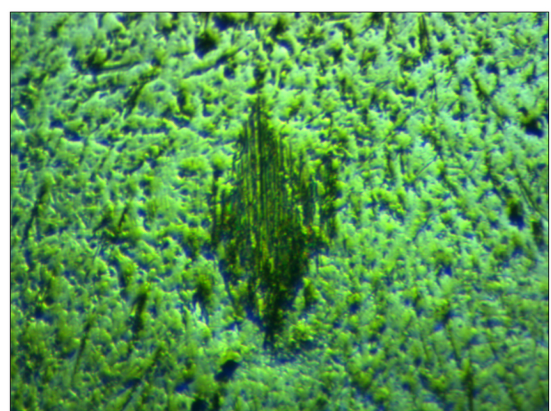

(a)

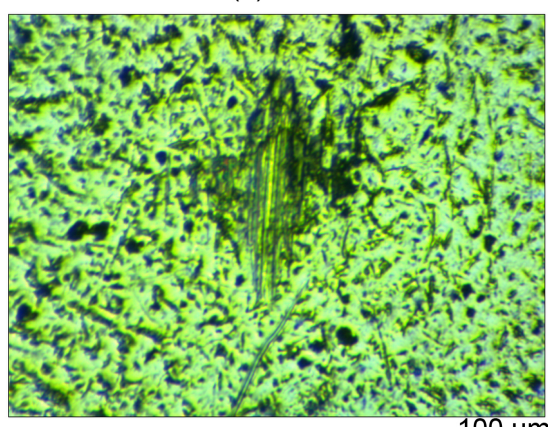

(b)

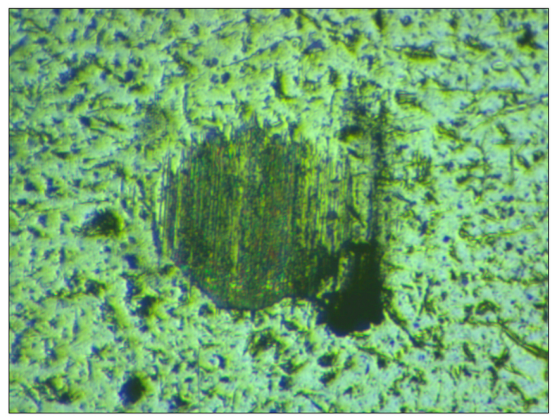

(c)

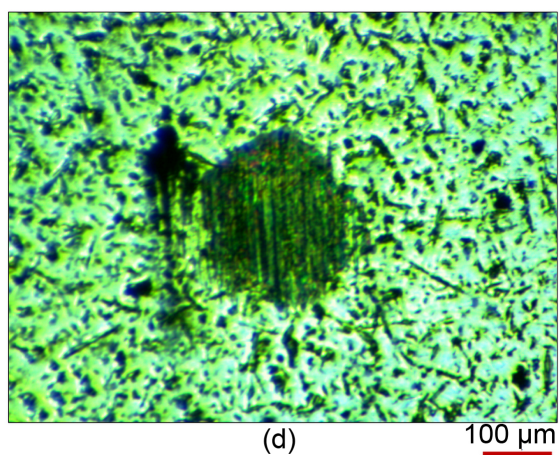

(d)

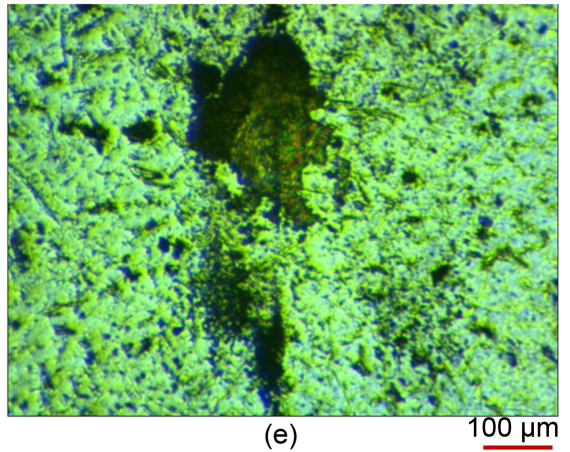

(e)

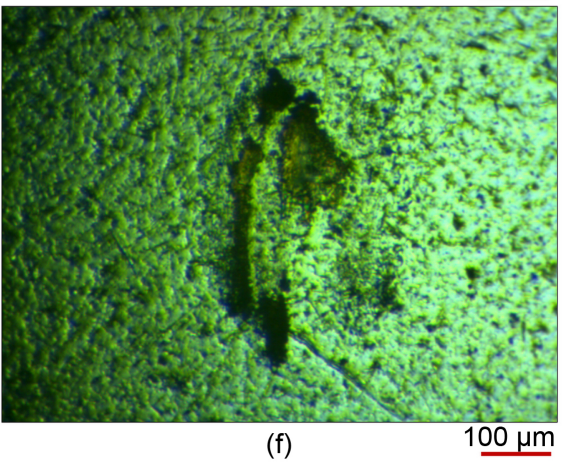

(f)

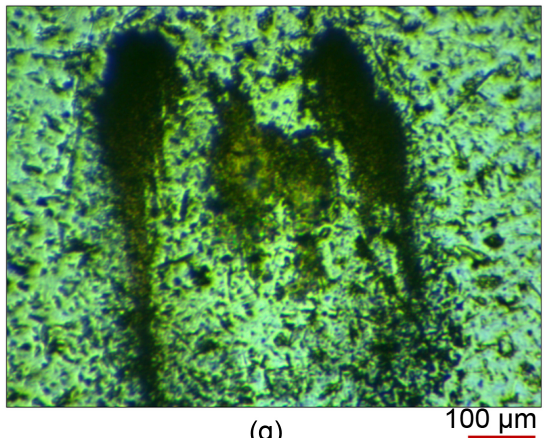

(g)

Figure 4. Optical micrographs of the wear scars during friction testing of the films in ambient air. (a) DLC; (b) 0.6 at.\% F-DLC; (c) 1.2 at.\% F-DLC; (d) 2.1 at.\% F-DLC; (e) 26.7 at.\% Si-DLC; (f) 32.2 at.\% Si-DLC; (g) 38.4 at.\% Si-DLC.

on the ball surfaces plays an important role in reducing the friction coefficient of the Si-DLC films.

\subsection{Friction Tests Measured in Dry Air}

However, the tribological behavior of DLC films remains sensitive to the envi- 
ronment, especially to the relative humidity $(\mathrm{RH})$ [32] [43]. To understanding the friction behavior of these films, the friction coefficients and optical micrographs were also measured in dry air, as shown in Figure 5 and Figure 6 respectively. As shown in these figures, the results indicated that the friction coefficient of a pure DLC film showed a very low friction coefficient and was in the range from 0.02 to 0.04 . This was evidence by a small wear scar and transfer layer

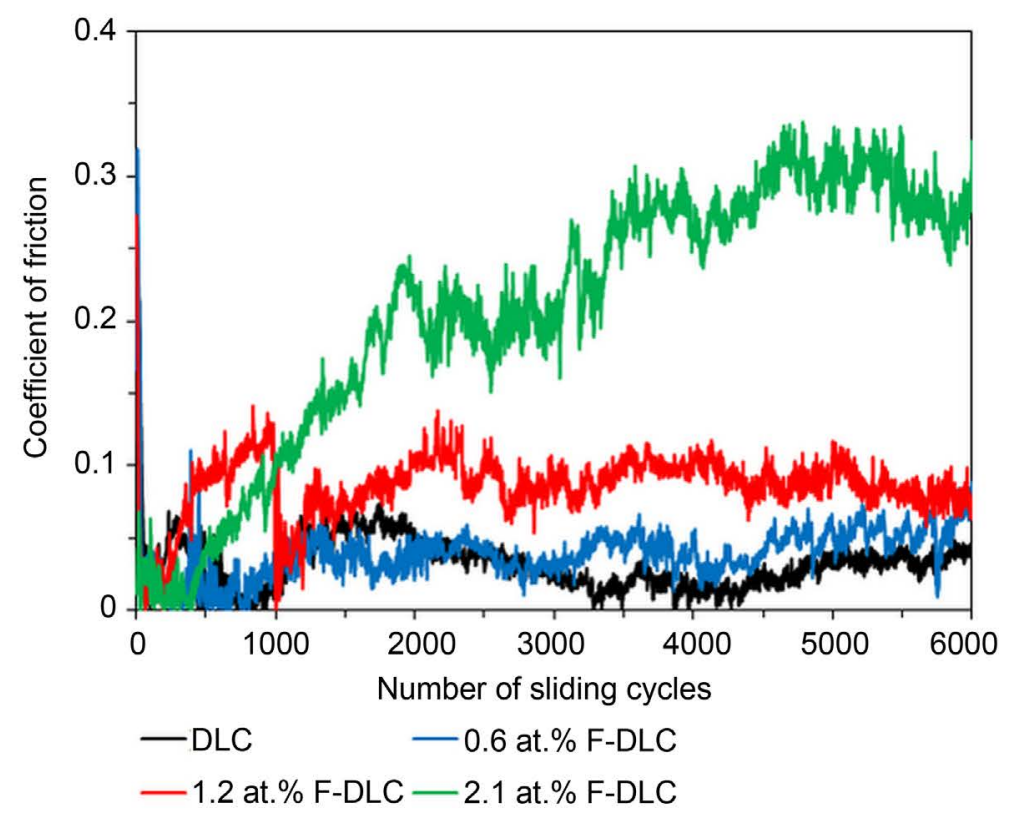

(a)

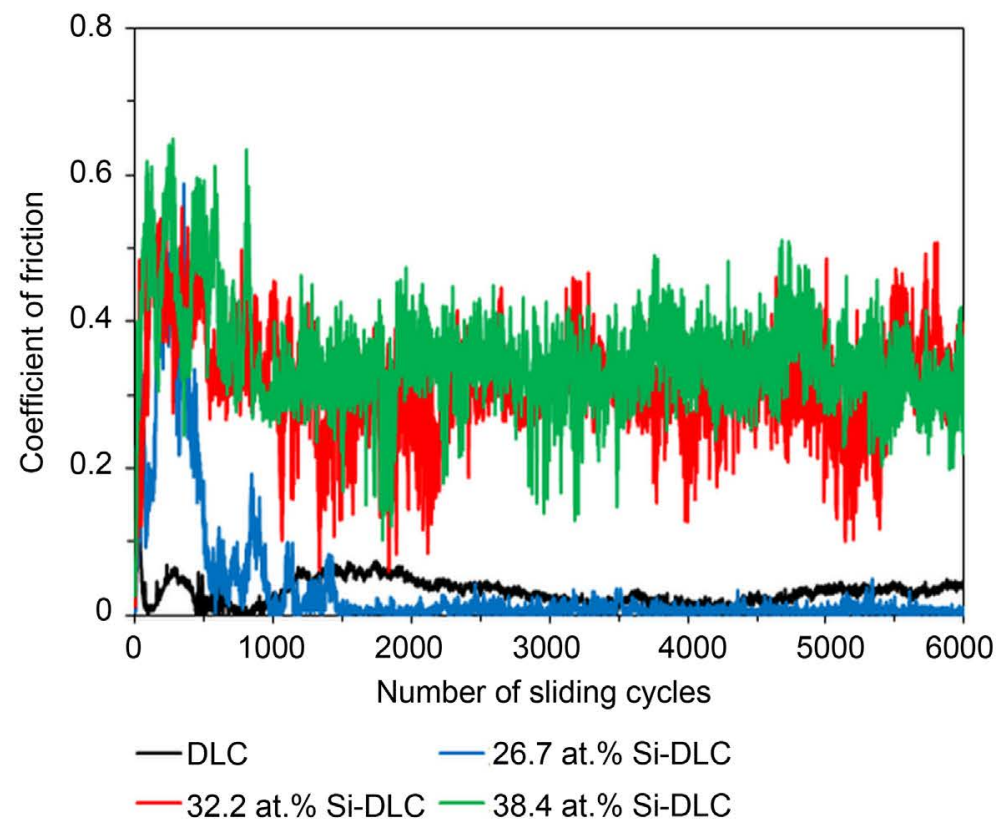

(b)

Figure 5. Friction coefficients of the films with different $\mathrm{F}$ and $\mathrm{Si}$ contents compared to that of a pure DLC film measured in dry air. (a) F-DLC films; (b) Si-DLC films. 


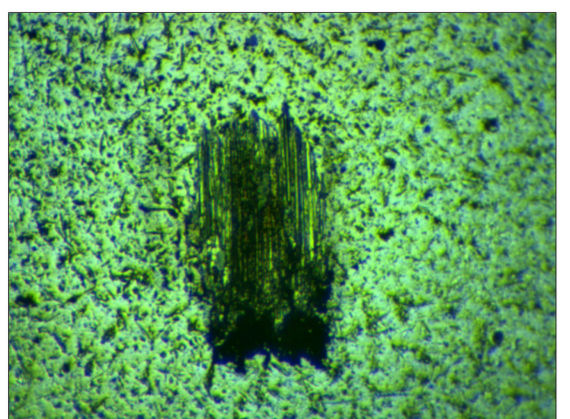

(a)

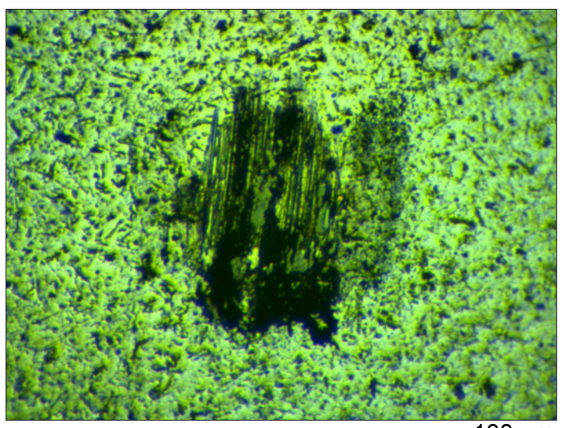

(b)

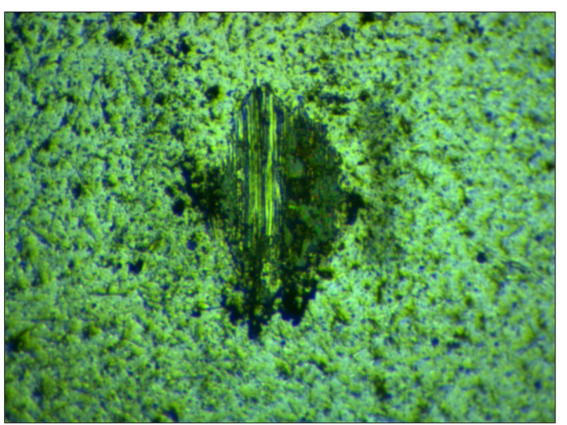

(c)

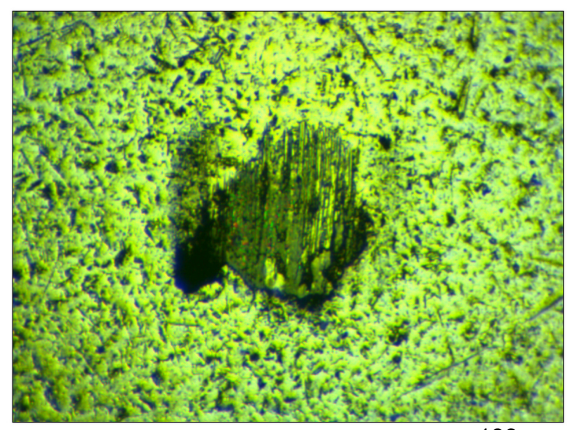

(d)

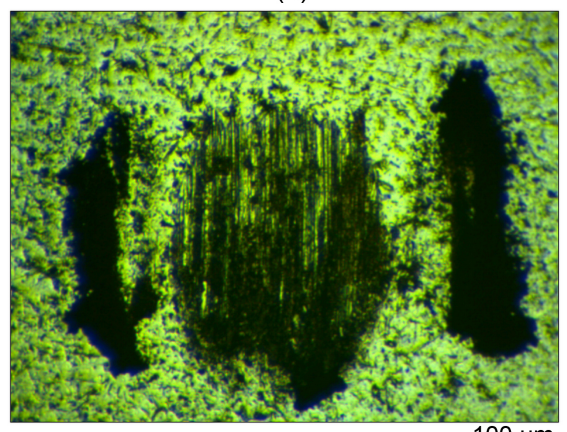

(e)

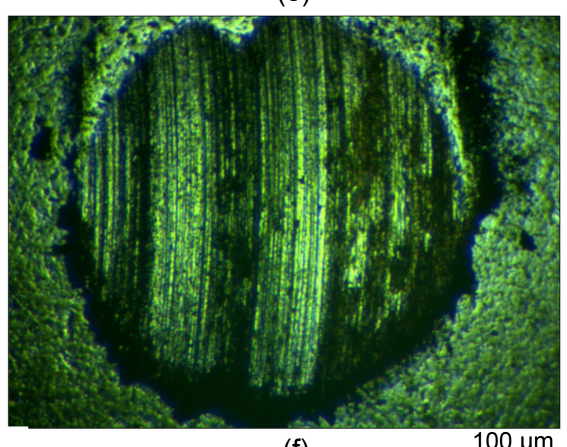

(f)

$100 \mu \mathrm{m}$

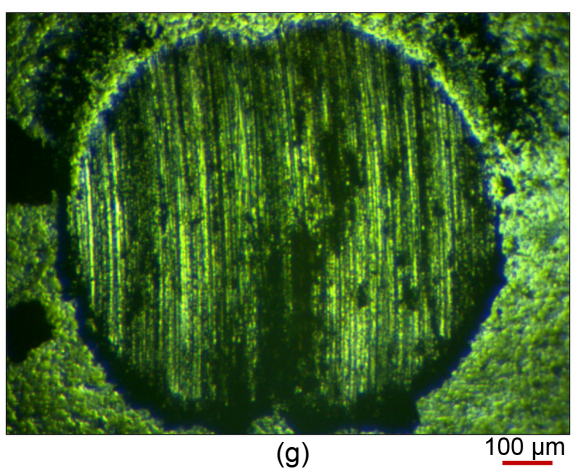

(g)

Figure 6. Optical micrographs of the wear scars during friction testing of the films in dry air. (a) DLC; (b) 0.6 at.\% F-DLC; (c) 1.2 at.\% F-DLC; (d) 2.1 at.\% F-DLC; (e) 26.7 at.\% Si-DLC; (f) 32.2 at.\% Si-DLC; (g) 38.4 at.\% Si-DLC.

formed on the ball surfaces (Figure 6(a)). When the F and Si contents were incorporated into DLC films, the friction behavior of F-DLC and Si-DLC films presented two opposite trends. One is the friction reduction for DLC films with lower $\mathrm{F}$ and Si contents ( 0.6 at.\% F and 26.7 at.\% Si, respectively) and another is 
the significant friction increment for DLC films with higher F and Si contents.

For the F-DLC films (Figure 5(a)), it was proposed that the repulsive force originating from fluorinated transfer layer between two surfaces is responsible for the low friction coefficient of the DLC film with 0.6 at.\% F and was in the range from 0.02 to 0.04 . The accumulated $\mathrm{F}$ atoms on a transfer layer reduced interface adhesion due to repulsion between $\mathrm{F}$ atoms, resulting in a low friction coefficient. This was evidenced by the wear scar formed on the ball surfaces, as shown in Figure 6(b). However, the presence of less transfer layer on the ball surfaces was observed for the DLC film with 1.2 and 2.1 at.\% F, as shown in Figure 6(c) and Figure 6(d). This result indicated an increase in the shear resistance of the layer, resulting in a higher friction coefficient of the films. Consequently, the formation of fluorinated transfer layer plays an important role in the friction mechanism of F-DLC films.

For the Si-DLC films (Figure 5(b)), the 26.7 at.\% Si-DLC film showed a very low friction coefficient of approximately 0.01 . Evidence of material transfer was observed on the ball surfaces (Figure 6(e)). This can be ascribed to the fact that the formation of silicon-rich transfer layer on the ball surfaces plays an important role in reducing the friction coefficient of the film. In contrast, the 32.2 and 38.4 at.\% Si-DLC films exhibited higher friction coefficients and were in the range from 0.3 to 0.4 . A large wear scar formed on the ball surfaces was strongly affected to a high friction coefficient of the film (Figure 6(f) and Figure 6(g)). The uniform wearing with a large wear scar was observed, while the accumulated debris formed and covered near the wear scar was slightly illustrated. Therefore, a small amount of the formation of an oxide layer is probably the reason for the high friction coefficient.

\section{Conclusion}

DLC films with variable F and Si contents were synthesized on Si (100) wafers using the PBII technique. The films were investigated to determine the effects of elemental doping on the tribological properties. The deposited DLC film had small amounts of $\mathrm{F}$ and large amounts of $\mathrm{Si}$, which were proportional to the gas ratio of $\mathrm{CF}_{4}$ and TMS, respectively. The G-peak position shifted to higher wavenumbers with an increase in the F content, leading to a decrease in the hardness and elastic modulus, whereas the shift in the G-peak position to lower wavenumbers with an increase in the Si content indicated an increase in the hardness and elastic modulus. The change in the hardness and elastic modulus was related to the change in the microstructure corresponding to the $\mathrm{sp}^{3}$ bonding fraction in the film. Furthermore, DLC films with added Si exhibited low friction coefficients when measured in ambient air, while DLC films with added $\mathrm{F}$ showed a slight reduction in the friction coefficients compared with the pure DLC. When measured in dry air, only the 26.7 at.\% Si-DLC film presented a very low friction coefficient. The friction behaviors were corroborated by the wear scars. For the aforementioned reasons, it can be concluded that the Si with 26.7 at.\% content in 
a DLC film did improve the tribological performance of the materials.

\section{Acknowledgements}

This work was supported by a grant from the King Mongkut's University of Technology Thonburi (KMUTT) Research Fund.

\section{Conflicts of Interest}

The authors declare no conflicts of interest regarding the publication of this paper.

\section{References}

[1] Robertson, J. (2002) Diamond-Like Amorphous Carbon. Materials Science and Engineering: $R$, 37, 129-281. https://doi.org/10.1016/S0927-796X(02)00005-0

[2] Cho, S.-J., Chung, J.-W. and Lee, K.-R. (2005) Characterization of the Mechanical Properties of Diamond-Like Carbon Films. Diamond and Related Materials, 14, 1270-1276. https://doi.org/10.1016/j.diamond.2004.11.034

[3] Singh, R.A., Yoon, E.-S., Kim, H.J., Kong, H., Park, S.-J. and Lee, K.-R. (2006) Friction Behaviour of Diamond-Like Carbon Films with Varying Mechanical Properties. Surface and Coatings Technology, 201, 4348-4351. https://doi.org/10.1016/j.surfcoat.2006.08.055

[4] Zou, C.W., Wang, H.J., Feng, L. and Xue, S.W. (2013) Effects of Cr Concentrations on the Microstructure, Hardness, and Temperature-Dependent Tribological Properties of Cr-DLC Coatings. Applied Surface Science, 286, 137-141. https://doi.org/10.1016/j.apsusc.2013.09.036

[5] Park, S.-J., Lee, K.-R. and Ko, D.H. (2004) Tribochemical Reaction of Hydrogenated Diamond-Like Carbon Films: A Clue to Understand the Environmental Dependence. Tribology International, 37, 913-921.

https://doi.org/10.1016/j.triboint.2004.07.008

[6] Rubio-Roy, M., Corbella, C., Bertran, E., Portal, S., Polo, M.C., Pascual, E. and Andújar, J.L. (2009) Effects of Environmental Conditions on Fluorinated DiamondLike Carbon Tribology. Diamond and Related Materials, 18, 923-926.

https://doi.org/10.1016/j.diamond.2009.02.006

[7] Hakovirta, M., He, X.M. and Nastasi, M. (2000) Optical Properties of Fluorinated Diamond-Like Carbon Films Produced by Pulsed Glow Discharge Plasma Immersion Ion Processing. Journal of Applied Physics, 88, 1456-1459. https://doi.org/10.1063/1.373838

[8] Prioli, R., Jacobsohn, L.G., H. Maia-da-Costa, M.E. and Freire-Jr., F.L. (2003) Nanotribological Properties of Amorphous Carbon-Fluorine Films. Tribology Letters, 15, 177-180. https://doi.org/10.1023/A:1024848816646

[9] Papakonstantinou, P., Zhao, J.F., Lemoine, P., McAdams, E.T. and McLaughlin, J.A. (2002) The Effects of Si Incorporation on the Electrochemical and Nanomechanical Properties of DLC Thin Films. Diamond and Related Materials, 11, 1074-1080. https://doi.org/10.1016/S0925-9635(01)00656-2

[10] Lee, K.-R., Kim, M.-G., Cho, S.-J., Eun, K.Y. and Seong, T.-Y. (1997) Structural Dependence of Mechanical Properties of Si Incorporated Diamond-Like Carbon Films Deposited by RF Plasma-Assisted Chemical Vapour Deposition. Thin Solid Films, 308-309, 263-267. https://doi.org/10.1016/S0040-6090(97)00411-2 
[11] Jongwannasiri, C. and Watanabe, S. (2016) Tribological Behavior of O2 and CF4 Plasma Post-Treated Diamond-Like Carbon Films under Dry Air and in a High Relative Humidity Environment. Surface and Coatings Technology, 306, 200-204. https://doi.org/10.1016/j.surfcoat.2016.05.082

[12] Wang, J., Pu, J., Zhang, G. and Wang, L. (2013) Tailoring the Structure and Property of Silicon-Doped Diamond-Like Carbon Films by Controlling the Silicon Content. Surface and Coatings Technology, 235, 326-332.

https://doi.org/10.1016/j.surfcoat.2013.07.061

[13] Capano, M.A., McDevitt, N.T., Singh, R.K. and Qian, F. (1996) Characterization of Amorphous Carbon Thin Films. Journal of Vacuum Science and Technology A, 14, 431-435. https://doi.org/10.1116/1.580101

[14] Yu, G.Q., Tay, B.K., Sun, Z. and Pan, L.K. (2003) Properties of Fluorinated Amorphous Diamond Like Carbon Films by PECVD. Applied Surface Science, 219, 228-237. https://doi.org/10.1016/S0169-4332(03)00644-5

[15] Ishihara, M., Kosaka, T., Nakamura, T., Tsugawa, K., Hasegawa, M., Kokai, F. and Koga, Y. (2006) Antibacterial Activity of Fluorine Incorporated DLC Films. Diamond and Related Materials, 15, 1011-1014. https://doi.org/10.1016/j.diamond.2005.12.037

[16] Bendavid, A., Martin, P.J., Randeniya, L. and Amin, M.S. (2009) The Properties of Fluorine Containing Diamond-Like Carbon Films Prepared by Plasma-Enhanced Chemical Vapour Deposition. Diamond and Related Materials, 18, 66-71. https://doi.org/10.1016/j.diamond.2008.09.021

[17] Ferrari, A.C. and Robertson, J. (2000) Interpretation of Raman Spectra of Disordered and Amorphous Carbon. Physical Review B, 61, 14095-14107. https://doi.org/10.1103/PhysRevB.61.14095

[18] Yao, Z.Q., Yang, P., Huang, N., Sun, H. and Wang, J. (2004) Structural, Mechanical and Hydrophobic Properties of Fluorine-Doped Diamond-Like Carbon Films Synthesized by Plasma Immersion Ion Implantation and Deposition (PIII-D). Applied Surface Science, 230, 172-178. https://doi.org/10.1016/j.apsusc.2004.02.044

[19] Goyenola, C., Stafström, S., Schmidt, S., Hultman, L. and Gueorguiev, G.K. (2014) Carbon Fluoride, CFx: Structural Diversity as Predicted by First Principles. The Journal of Physical Chemistry C, 118, 6514-6521. https://doi.org/10.1021/jp500653c

[20] Wang, J., Ma, J., Huang, W., Wang, L., He, H. and Liu, C. (2017) The Investigation of the Structures and Tribological Properties of F-DLC Coatings Deposited on Ti-6Al-4V Alloys. Surface and Coatings Technology, 316, 22-29. https://doi.org/10.1016/j.surfcoat.2017.02.065

[21] Lee, S., Kim, D.S., Rhee, S.G., Oh, S.G. and Lee, K.R. (1999) Structure and Optical Properties of Si Incorporated Diamond-Like Carbon Films Deposited by r.f. Plasma-Assisted Chemical Vapor Deposition. Thin Solid Films, 341, 68-72.

https://doi.org/10.1016/S0040-6090(98)01527-2

[22] Ray, S.C., Bao, C.W., Tsai, H.M., Chiou, J.W., Jan, J.C., Tsai, M.-H., Wang, W.-J., Hsu, C.-J., Okpalugo, T.I.T., Papakonstantinou, P. and McLaughlin, J.A. (2004) Electronic Structure and Bonding Properties of Si-Doped Hydrogenated Amorphous Carbon Films. Applied Physics Letters, 85, 4022-4024. https://doi.org/10.1063/1.1812594

[23] Meneve, J., Dekempeneer, E. and Smeets, J. (1994) a-Si1-xCx:H Films and Their Possibilities and Limitations for Tribological Applications. Diamond Films and Technology, 4, 23-36.

[24] Bendavid, A., Martin, P.J., Comte, C., Preston, E.D., Haq, A.J., Magdon-Ismail, F.S. 
and Singh, R.K. (2007) The Mechanical and Biocompatibility Properties of DLC-Si Films Prepared by Pulsed DC Plasma Activated Chemical Vapor Deposition. Diamond and Related Materials, 16, 1616-1622. https://doi.org/10.1016/j.diamond.2007.02.006

[25] Trippe, S.C., Mansano, R.D., Costa, F.M. and Silva, R.F. (2004) Mechanical Properties Evaluation of Fluor-Doped Diamond-Like Carbon Coatings by Nanoindentation. Thin Solid Films, 446, 85-90. https://doi.org/10.1016/j.tsf.2003.08.069

[26] Jacobsohn, L.G., Camargo-Jr., S.S. and Freire-Jr., F.L. (2002) Fluorinated a-C:H Films Investigated by Thermal-Induced Gas Effusion. Diamond and Related Materials, 11, 1831-1836. https://doi.org/10.1016/S0925-9635(02)00167-X

[27] Fujimoto, S., Ohtake, N. and Takai, O. (2011) Mechanical Properties of SiliconDoped Diamond-Like Carbon Films Prepared by Pulse-Plasma Chemical Vapor Deposition. Surface and Coatings Technology, 206, 1011-1015. https://doi.org/10.1016/j.surfcoat.2011.03.106

[28] Pauleau, Y. (2001) Generation and Evolution of Residual Stresses in Physical Vapour-Deposited Thin Films. Vacuum, 61, 175-181. https://doi.org/10.1016/S0042-207X(00)00475-9

[29] Pierson, H.O. (1993) Handbook of Carbon, Graphite, Diamond and Fullerenes. Noyes Publications, Park Ridge.

[30] Erdemir, A. (2001) The Role of Hydrogen in Tribological Properties of DiamondLike Carbon Films. Surface and Coatings Technology, 146-147, 292-297. https://doi.org/10.1016/S0257-8972(01)01417-7

[31] Donnet, C., Fontaine, J., Grill, A. and Mogne, T.L. (2001) The Role of Hydrogen on the Friction Mechanism of Diamond-Like Carbon Films. Tribology Letters, 9, 137142. https://doi.org/10.1023/A:1018800719806

[32] Erdemir, A. and Donnet, C. (2006) Tribology of Diamond-Like Carbon Films: Recent Progress and Future Prospects. Journal of Physics D: Applied Physics, 39, R311R327. https://doi.org/10.1088/0022-3727/39/18/R01

[33] Zhang, L., Wang, F., Qiang, L., Gao, K., Zhang, B. and Zhang, J. (2015) Recent Advances in the Mechanical and Tribological Properties of Fluorine-Containing DLC Films. RSC Advances, 5, 9635-9649. https://doi.org/10.1039/C4RA14078H

[34] Allred, A.L. (1961) Electronegativity Values from Thermochemical Data. Journal of Inorganic and Nuclear Chemistry, 17, 215-221. https://doi.org/10.1016/0022-1902(61)80142-5

[35] Oguri, K. and Arai, T. (1991) Tribological Properties and Characterization of Diamond-Like Carbon Coatings with Silicon Prepared by Plasma-Assisted Chemical Vapour Deposition. Surface and Coatings Technology, 47, 710-721. https://doi.org/10.1016/0257-8972(91)90344-V

[36] Oguri, K. and Arai, T. (1992) Two Different Low Friction Mechanisms of Diamond-Like Carbon with Silicon Coatings Formed by Plasma-Assisted Chemical Vapor Deposition. Journal of Materials Research, 7, 1313-1316. https://doi.org/10.1557/JMR.1992.1313

[37] Yang, S.H., Kong, H., Lee, K.-R., Park, S. and Kim, D.E. (2002) Effect of Environment on the Tribological Behavior of Si-Incorporated Diamond-Like Carbon Films. Wear, 252, 70-79. https://doi.org/10.1016/S0043-1648(01)00856-0

[38] Liu, Y., Erdemir, A. and Meletis, E. (1996) An Investigation of the Relationship between Graphitization and Frictional Behavior of DLC Coatings. Surface and Coatings Technology, 86-87, 564-568. https://doi.org/10.1016/S0257-8972(96)03057-5

[39] Sanchez-Lopez, J., Erdemir, A., Donnet, C. and Rojas, T. (2003) Friction-Induced 
Structural Transformations of Diamondlike Carbon Coatings under Various Atmospheres. Surface and Coatings Technology, 163-164, 444-450.

https://doi.org/10.1016/S0257-8972(02)00641-2

[40] Fontaine, J., LeMogne, T., Loubet, J. and Belin, M. (2005) Achieving Superlow Friction with Hydrogenated Amorphous Carbon: Some Key Requirements. Thin Solid Films, 482, 99-108. https://doi.org/10.1016/j.tsf.2004.11.126

[41] Sen, F.G., Qi, Y. and Alpas, A.T. (2011) Material Transfer Mechanisms between Aluminum and Fluorinated Carbon Interfaces. Acta Materialia, 59, 2601-2614. https://doi.org/10.1016/j.actamat.2010.12.045

[42] Kim, M.-G., Lee, K.-R. and Eun, K.Y. (1999) Tribological Behavior of Silicon-Incorporated Diamond-Like Carbon Films. Surface and Coatings Technology, 112, 204-209. https://doi.org/10.1016/S0257-8972(98)00770-1

[43] Donnet, C., Belin, M., Auge, J.C., Martin, J.M., Grill, A. and Patel, V. (1994) Tribochemistry of Diamond-Like Carbon Coatings in Various Environments. Surface and Coatings Technology, 68-69, 626-631.

https://doi.org/10.1016/0257-8972(94)90228-3 